\title{
The Burden of Inpatient Neurologic Disease in a Tropical African Hospital
}

\author{
E.E. Philip-Ephraim, K.I. Eyong, S. Chinenye, U.E. William, R.P. Ephraim
}

\begin{abstract}
Background: Neurologic disorders represent a major burden of disease globally and the spectrum ranges from noncommunicable disorders like stroke and neurodegenerative disorders to central nervous system infections. Objective: The purpose of the study is to assess the burden of neurological diseases in a tropical environment. Methods: A one year retrospective survey of neurological diseases seen at the University of Calabar Teaching Hospital, Nigeria, was evaluated using patients' medical record. Results: Neurological diseases constituted $24.2 \%$ of all medical conditions seen over a one year period. Stroke was found to be the commonest cause of admissions accounting for $42.1 \%$ of the cases followed by peripheral neuropathy (13.8\%) and meningoencephalitis $(7.2 \%)$. The immediate case fatality rate was $33.6 \%$. Fifty two percent were discharged home with various levels of recovery while $12.5 \%$ left against medical advice. About $2 \%$ were referred to other tertiary health institutions. Conclusion: The pattern of neurologic diseases in the local medical wards was not remarkably different from those observed in Nigeria and elsewhere. Stroke remains the most frequent cause of neurologic admissions and mortality in this region is same as observed elsewhere.
\end{abstract}

RÉSUMÉ: Le fardeau des maladies neurologiques chez les patients hospitalisés dans un hôpital de l'Afrique tropicale. Contexte : Les maladies neurologiques constituent un fardeau majeur au niveau mondial et leur éventail va de maladies non contagieuses, comme l'accident vasculaire cérébral et les maladies neurodégénératives, aux infections du système nerveux central. Objectif : Le but de l'étude était d'évaluer le fardeau que constituent les maladies neurologiques dans cet environnement tropical. Méthode : Nous avons effectué une étude rétrospective des dossiers des patients atteints d'une maladie neurologique, admis à l'Hôpital universitaire de Calabar, au Nigeria. Résultats : Au cours d'une année, 24,2\% des patients admis étaient atteints d'une maladie neurologique. L'accident vasculaire cérébral était la plus fréquente, soit $42,1 \%$ de ces patients, suivi de la neuropathie périphérique $(13,8 \%)$ et de la méningoencéphalite $(7,2 \%)$. Le taux de létalité immédiate était de 33,6\%. Cinquante-deux pour cent des patients ont quitté l'hôpital pour rentrer chez-eux avec des niveaux de récupération variés à leur sortie de l'hôpital et $12,5 \%$ des patients ont quitté l'hôpital contre l'avis du médecin. Environ $2 \%$ ont été référés à d'autres institutions de soins tertiaires. Conclusion : L'éventail des maladies neurologiques dans ce service de médecine n'était pas remarquablement différent de celui observé dans le pays et ailleurs dans le monde. L'accident vasculaire cérébral demeure la cause la plus fréquente d'admission en neurologie et la mortalité dans cette région est la même que celle observée ailleurs dans le monde.

Can J Neurol Sci. 2013; 40: 576-579

\section{INTRODUCTION}

Neurologic disorders represent a major burden of disease globally ${ }^{1}$. The spectrum ranges from non-communicable disorders like stroke and neurodegenerative disorders to neurological infections like meningitis and tetanus. These contribute considerably to the high burden of diseases ${ }^{2}$. The spectrum of these neurologic diseases in Calabar, Nigeria is not known. The knowledge of the spectrum of neurological diseases can help define ways of improving both the management and outcome of these disorders. The study was undertaken to determine the types, frequency and outcome associated with these neurologic conditions admitted into the medical wards of our hospital and to compare these with similar studies elsewhere.

\section{MethodologY}

The study was carried out in the only teaching hospital in the Cross River state of Nigeria, which has a wide catchment area particularly for neurologic diseases. We reviewed the records of all the adult in-patients in the medical wards of the University of Calabar Teaching Hospital, Calabar, Nigeria from May 2009 to April 2010. The University of Calabar Teaching Hospital is a tertiary hospital in Calabar, the capital of Cross River State, in south eastern Nigeria. The population of Cross River State is $2,888,966$ based on the 2006 population census ${ }^{3}$.

The patients admitted into the medical wards are usually recruited from both the medical out-patients and the emergency departments of the hospital. Data extracted from the register in the wards were age, sex, diagnosis and outcome (this concerned discharged cases, mortality, referrals, and those that left against medical advice-LAMA/ absconded). Inclusion criteria were patients who were aged 14 years and older admitted into the medical wards. Patients excluded were those less than 14 years and those with incomplete data. Some of the diagnoses were

\footnotetext{
From the Department of Internal Medicine (EEPE, UEW, RPE), Department of Paediatrics (KIE), University of Calabar Teaching Hospital, Calabar; Department of Internal Medicine (SC), University of Port Harcourt Teaching Hospital, Port Harcourt, Nigeria.

Received November 6, 2012. Final Revisions Submitted February 15, 2013 Correspondence to: Ekanem E. Philip-Ephraim, Department of Internal Medicine, University of Calabar Teaching Hospital, PMB 1278, Calabar, Nigeria.
} 
Table 1: Distribution of neurological disorders by sex

\begin{tabular}{lcccc}
\hline Diagnosis & Male & Female & Total & Percentage \\
\hline Stroke & 43 & 21 & 64 & 42.1 \\
Peripheral neuropathy & 13 & 8 & 21 & 13.8 \\
Meningoencephalitis & 8 & 3 & 11 & 7.2 \\
Hepatic encephalopathy & 5 & - & 5 & 3.3 \\
Tetanus & 5 & 1 & 6 & 3.9 \\
Spinal cord disorders & 6 & 1 & 7 & 4.6 \\
Hypertensive encephalopathy & 5 & 3 & 8 & 5.3 \\
Parkinson's disease & 4 & - & 4 & 2.6 \\
Acute confusional state & 4 & 4 & 8 & 5.3 \\
Brain tumours & 2 & 3 & 5 & 3.3 \\
Transient ischaemic attack & 1 & 1 & 2 & 1.3 \\
Bell's palsy & 2 & - & 2 & 1.3 \\
Cognitive impairment & - & 1 & 1 & 0.7 \\
\hline Total & 103 & 49 & 152 & 100 \\
\hline
\end{tabular}

made purely on clinical grounds while some had laboratory supports.

The data was analyzed using the Epi Info software. Results were presented in simple frequency table proportions.

\section{Results}

Of the 699 medical cases admitted during the study period, 169 were neurological cases. This constituted $24.2 \%$ of the total medical admissions during the study period. Seventeen of these patients were excluded from further analysis due to incomplete data. That brought the total number of neurological cases reviewed in this study to 152 . The sex distribution of patients was $103(68 \%)$ males and $49(32 \%)$ females giving a sex ratio of
2.1:1. The ages of the patients ranged from 14 years to 83 years with a mean of 51.2 years and a median of 52 years.

Table 1 shows the distribution of neurological disorders by gender. The commonest disorder was stroke followed by peripheral neuropathy and meningoencephalitis.

Table 2 shows the outcome of the various neurological diseases. Fatality rates ranged from nil percent for spinal cord diseases, Parkinson's disease, transient ischaemic attack, Bell's palsy and cognitive impairment to $40.6 \%$ for stroke. The total outcome of the neurologic diseases showed that $79(52 \%)$ of the cases were discharged home, 51 (33.6\%) died, 19 (12.5\%) left against medical advice, $3(1.9 \%)$ of the patients were referred to other tertiary hospitals and none absconded during the study period. The mortality rate represented $7.3 \%$ of the medical deaths.

\section{DISCUSSION}

This study has shown that neurologic diseases are common in Calabar, south eastern Nigeria. The spectrum of neurological diseases was stroke, peripheral neuropathy(mainly from diabetes mellitus), meningoencephalitis, hepatic encephalopathy, tetanus, spinal cord disorders, HIV encephalopathy, Parkinson's disease, acute confusional state, brain tumour, transient ischaemic attack, Bell's palsy and cognitive impairment.

These disorders constituted $24.2 \%$ of the total medical admissions during the study period. This value was slightly higher than that reported by Ojini (19.6\%) in Lagos and Ogun et al $(19.6 \%)$ in Sagamu, both in Nigeria ${ }^{4,5}$ was lower than that reported by Chapp- Jumbo in Port Harcourt, Nigeria where neurological diseases constituted $33.1 \%$ of medical admissions ${ }^{6}$. Reports from previous studies in Nigeria, had recorded lower values $^{7-9}$. There was a notable sex predilection in these diseases as there were more males than females with a male to female sex ratio of 2.1: 1. Other studies had also demonstrated neurological diseases to be more frequent among men than women ${ }^{8,10,11}$.

Table 2: Outcome of neurological diseases

\begin{tabular}{lccccc}
\hline $\begin{array}{l}\text { Neurological } \\
\text { Condition }\end{array}$ & $\begin{array}{c}\text { Total } \\
\text { Case fatality } \\
\mathrm{n}(\%)\end{array}$ & $\begin{array}{c}\text { Discharge } \\
\mathrm{n}(\%)\end{array}$ & $\begin{array}{c}\text { Referred } \\
\mathrm{n}(\%)\end{array}$ & $\begin{array}{c}\text { LAMA } \\
\mathrm{n}(\%)\end{array}$ \\
\hline Stroke & 64 & $26(40.6)$ & $30(46.9)$ & $1(1.6)$ & $7(10.9)$ \\
DM neuropathy & 21 & $5(23.8)$ & $13(61.9)$ & - & $3(14.3)$ \\
Meningo-encephalitis & 11 & $6(54.5)$ & $3(27.3)$ & - & $2(18.2)$ \\
Hypertensive encephalopathy & 8 & $3(37.5)$ & $4(50.0)$ & - & $1(12.5)$ \\
HIV Encephalopathy & 8 & $4(50.0)$ & $3(37.5)$ & - & $1(12.5)$ \\
Acute confusional State & 8 & $2(25.0)$ & $6(75.0)$ & - & - \\
Spinal cord diseases & 7 & - & $6(85.7)$ & - & $1(14.3)$ \\
Tetanus & 6 & $2(33.3)$ & $2(33.3)$ & - & $2(33.3)$ \\
Hepatic encephalopathy & 5 & $2(40.0)$ & $2(40.0)$ & - & $1(20.0)$ \\
Brain tumour & 5 & $1(20.0)$ & $1(20.0)$ & $2(40.0)$ & $1(20.0)$ \\
Parkinson's Disease & 4 & - & $4(100.0)$ & - & - \\
Transient ischaemic attack & 2 & - & $2(100.0)$ & - & - \\
Bell's palsy & 2 & - & $2(100.0)$ & - & - \\
Cognitive Impairment & 1 & - & $1(100.0)$ & - & - \\
\hline Total & 152 & 51 & 79 & 3 & 19 \\
\hline
\end{tabular}


However a study carried out by Ekenze et al in Enugu, Nigeria, showed no significant sex predilection in neurological diseases ${ }^{7}$.

The three most common neurological cases admitted during the study period were stroke, peripheral neuropathy (mainly from diabetes mellitus) and meningoencephalitis. Hypertensive encephalopathy, HIV encephalopathy, acute confusional state and spinal cord diseases were also common. Epilepsy and Guillain Barre were rare in our study. The diagnosis of stroke was made purely on clinical grounds due to the lack of computed tomography (CT) scan in the hospital during the study period. Studies have shown that clinical examination alone is unreliable in distinguishing ischemic from haemorrhagic stroke hence the need for imaging techniques like the CT $\operatorname{scan}^{12,13}$. In the absence of a CT scan, stroke subtypes, hemorrhagic and ischemic, have been classified using Siriraj and Allen scoring systems. In a prospective study carried out in Tanzania, East Africa, both the Siriraj and Allen scoring systems were found to be unsatisfactory in classifying stroke subtypes ${ }^{14}$. Weir et $\mathrm{al}^{15}$ had also confirmed the poor accuracy of stroke scoring systems in differentiating intracranial haemorrhage from infarction. In another study carried out by Nouira et $\mathrm{al}^{16}$ in Tunisia, North Africa, the use of Siriraj score was found to be valid and useful in predicting stroke subtypes. The scoring systems are therefore inconsistent and conflicting in differentiating the subtypes of stroke clinically. Our study was a retrospective one and the scoring systems were not applied. Stroke was observed to be the most frequent cause of neurologic admissions constituting $42.1 \%$ of such admissions. This study compares with similar studies in other parts of Nigeria where stroke was found to be the commonest cause of neurological admissions ${ }^{6,7,10,11}$. McLigeyo in the 1990's had also reported a high stroke frequency amongst geriatric admissions at the Kenyatta National Hospital, Kenya ${ }^{17}$. In addition, the peak age of admission for stroke was above 50 years, with the majority of the cases affecting those between 56 and 60 years. This goes to confirm findings from previous studies that found stroke to be a disease of the elderly $y^{5,6,18}$. This finding contrasted with earlier reports that stroke was more frequent below 50 years of age in Africans ${ }^{19,20}$. The high frequency of stroke in developing countries might be accounted for by the increasing prevalence of the traditional risk factors like hypertension (which increases with age), diabetes mellitus, hyperlipidemia and smoking, as more urbanized lifestyle is being adopted ${ }^{21}$.

Peripheral neuropathy, a microvascular complication of diabetes mellitus, was the second commonest neurologic disorder. The commonest presentation was that of distal symmetric polyneuropathy. Studies have also shown this to be the most frequent form of peripheral neuropathy in diabetes mellitus ${ }^{22}$. Diabetes mellitus is an increasing non-communicable disease in our environment. Particular challenges in management of diabetic peripheral neuropathy have not only been due to lack of screening, early detection, treatment and prevention of the disorder but also due to lack of awareness and poor foot care by patients ${ }^{23,24}$. The high incidence of diabetic peripheral neuropathy in our study is therefore not surprising.

Osuntokun in the 70's in Ibadan, Nigeria, had reported infections of the nervous system to be the commonest cause of neurological admissions ${ }^{18}$. Kwasa in Kenya had also observed central nervous system infections, mainly meningitis $(23.1 \%)$, to be the most frequent neurologic disorder ${ }^{9}$. In our study, meningoencephalitis ranked third as the commonest cause of admission. This confirms the changing pattern of neurologic illness in Africa.

The death rate and the percentage of those discharged were similar to that observed by Chapp-Jumbo in Niger Delta who reported a mortality rate of $36.5 \%$; and $56 \%$ for those discharged home $^{6}$. In an earlier study in Kano, Nigeria, Owolabi et al had reported a lower mortality rate of $22.4 \%$. The percentage of those who left against medical advice $(12.5 \%)$ was significantly higher in our study than the $5.8 \%$ and $0.8 \%$ reported by both Chapp- Jumbo in Port Harcourt, Nigeria and Owolabi et al in Kano, Nigeria respectively ${ }^{6,10}$.

The most frequent disease among spinal cord disorders was Pott's disease with peak age-range of 37-45 years. All the patients with the Pott's disease were males. This is similar to an earlier study that also found a male preponderance in those with Pott's disease $^{6}$. All the patients with the Pott's disease were discharged home.

The case fatality for stroke was $40.6 \%$. Stroke was thus found to be associated with high mortality. In a review by ChappJumbo, the mortality of stroke represented $65 \%$ of neurologic deaths ${ }^{6}$.

The case fatality rate for meningitis was $54.5 \%$ which is high compared to other studies. Lower case fatality rates were reported by Mobarak et al (17.6\%) in Egypt and Thigpen et al $(14.3 \%)$ in the United States ${ }^{25,26}$. This may reflect a higher standard of care and/or early presentation in these societies.

\section{CONCLUSION}

The pattern of neurologic diseases in our Nigerian hospital medical wards was not strikingly different from those observed in other parts of the country and elsewhere. Stroke remains the most frequent cause of neurologic admissions and the commonest cause of neurologic mortality in this region, as is observed elsewhere. Diabetic peripheral neuropathy and central nervous system infections including tetanus and meningoencephalitis were also common. Aside from Parkinson's disease, other movement disorders were very rare. Since stroke is a preventable neurologic condition, public campaigns on awareness and control of the risk factors should be carried out. Moreover, establishment of a well equipped stroke unit is encouraged in hospitals in our region. Good management of diabetes mellitus in our environment is a major challenge which if overcome, would reduce the incidence of neuropathy.

\section{ACKNOWLEDGEMENT}

The authors thank Professor Emmanuel E. Ekanem for his assistance in correcting the manuscript. 


\section{REFERENCES}

1. Murray CJL, Lopez AD. The global burden of disease. Cambridge: Havard School of Public Health. 1996.

2. Chapp-Jumbo EN. Neurological infections in a Nigerian University Teaching Hospital. Afr Health Sc. 2006;6(1):55-8.

3. Ottong JG, Ering SO, Akpan FU. The population situation in Cross River State of Nigeria and its implication for socio- economic development: observations from 1991 and 2006 Censuses. J emerging Trends in Edu Res and Pol Studies. 2010;1(1):36-42.

4. Ojini FI, Danesi M. The pattern of Neurological admissions at the Lagos University Teaching Hospital Nigeria. J Clin Prac. 2003;6 (1):38-44.

5. Ogun SA, Adelowo OO, Familoni OB, Jaiyesimi AE, Fakoya EA. Pattern and outcome of medical admissions at the Ogun State University Teaching Hospital, Sagamu- a three year review. West Afr J Med. 2000;19(4):304-8.

6. Chapp-Jumbo EN. Neurological Admissions in the Niger Delta area of Nigeria- A ten year review. Afr J Neurol Sc. 2004;23(1): $14-20$.

7. Ekenze OS, Onwuekwe IO, Ezeala Adikaibe BA. Profile of neurological admissions at the University of Nigeria Teaching Hospital, Enugu. Niger J Med. 2010;19(4):419-22.

8. Ike SO. The pattern of admissions into the medical wards of the University of Nigeria Teaching Hospital, Enugu (2). Niger J Clin Pract. 2008;11(3):185-92.

9. Kwasa TO. The pattern of neurological diseases at Kenyatta National Hospital. East Afr Med J. 1992;69(5):236-9.

10. Owolabi LF, Shehu MY, Shehu MN, Fadare J. Pattern of neurological admissions in the tropics: Experience at Kano, Northwestern Nigeria. Ann Indian Acad Neurol. 2010;13(3): 167-70.

11. Talabi OA. A 3-year review of neurologic admissions in University College Hospital Ibadan, Nigeria. West Afr J Med. 2003;22(2): $150-1$.

12. Shams-ur-Rehman, Khan MA. Clinical versus C.T. scan diagnosis in stroke- a comparative study of 50 cases. J Ayub Med Coll Abbotabad. 2002;14(1):2-5.

13. Khan J, Atique ur Rehman. Comparison of clinical diagnosis with computed tomography in ascertaining type of stroke. J Ayub Med Coll Abbotabad. 2005;17(3):1-3.
14. Walker RW, Jusabani A, Aris E, Gray WK, Mitra D, Swai M. A prospective study of stroke sub-type from within an incident population in Tanzania. S Afr Med J. 2011;101(5):338-44.

15. Weir CJ, Murray GD, Adams FG, Muir KW, Grosset DG, Lees KR. Poor accuracy of stroke scoring systems for differential clinical diagnosis of intracranial haemorrhage and infarction. Lancet. 1994;344(8928):999-1002.

16. Nouira S, Boukef R, Bouida W, et al. Accuracy of two scores in the diagnosis of stroke subtype in a multicenter cohort study. Ann Emerg Med. 2009;53:373-8.

17. McLigeyo SO. The pattern of geriatric admission in the medical wards at the Kenyattan National Hospital. East Afr Med J. 1993; 70(1):37-9.

18. Osuntokun BO. The pattern of neurological illness in tropical Africa: Experience at Ibadan, Nigeria. J Neurol Sci. 1971;12(4): 417-42.

19. Bonita R. Epidemiology of stroke. Lancet. 1992;339:342-4.

20. Abraham G, Abdulkadir J. Cerebrovascular accidents in Ethiopians. A review of 48 cases. East Afr Med J. 1981;58:431-6.

21. Brainin M, Teuschl Y, Kaira L. Acute treatment and long term management of stroke in developing countries. Lancet Neurol. 2007;6(6):553-61.

22. Bansal V, Kalita J, Misra UK. Diabetic neuropathy. Postgrad Med J. 2006;82(964):95-100.

23. Umoh VA, Otu AA, Enang OE, Okereke QO, Essien O, Ukpe I. The pattern of diabetic admissions in UCTH Calabar, south eastern Nigeria: a five year review. Niger Health J. 2012;12(1):7-11.

24. Ngim NE, Ndifon WO, Udosen AM, Ikpeme IA, Isiwele E. Lower limb amputation in diabetic foot disease: experience in a tertiary hospital in southern Nigeria. Afr J Diabetes Med. 2012;20(1): 13-5.

25. Mobarak EI. Trend, features and outcome of meningitis in the communicable disease hospital, Alexandra, Egypt, 1997-2006. J Egypt Public Health Assoc. 2012;87(1-2):16-23.

26. Thigpen MC, Whitney CG, Messonier NE, et al. Bacterial meningitis in the United States. N Engl J Med. 2011;364(21): 2016-25. 